\title{
Childhood Tuberculosis in Sub-saharan Africa
}

SA Kissou ${ }^{1,2,}$, JDC Millogo ${ }^{2}$, Z Nikiema $^{1,3}$, E Birba $^{1,4}$, R Cessouma $^{1,2}$, B Sanogo $^{2}$, PWH Dakouré $^{1,5}$ and B Nacro ${ }^{2}$

${ }^{1}$ Higher Institute of Health Sciences (INSSA), Nazi Boni University (UNB) of Bobo-Dioulasso, Burkina Faso

${ }^{2}$ Department of Pediatrics, Souro Sanou University Hospital Center(CHUSS), Bobo-Dioulasso, Burkina Faso

${ }^{3}$ Medical Imaging department, Souro Sanou University Hospital Center(CHUSS), Bobo-Dioulasso, Burkina Faso

${ }^{4}$ Pneumology/ptysiologydepartment, Souro Sanou University Hospital Center(CHUSS), Bobo-Dioulasso, Burkina Faso

${ }^{5}$ Orthopedic and trauma surgery department, Souro Sanou University Hospital Center(CHUSS), Bobo-Dioulasso, Burkina Faso

\section{Abstract}

Objective: Tuberculosis remains a public health problem in Burkina Faso and sub-Saharan Africa.The purpose of this study was to describe epidemiological, clinical and para-clinical aspects of childhood tuberculosis in sub-saharan hospital settings.

Methods: It was a cross-sectional study of new cases of tuberculosis diagnosed between 1st January 2016 and 31st December 2016 in the pediatric department of Bobo-Dioulasso University Hospital (Burkina Faso).

Results: The study included twenty eight (28) children with an average age of 8.3 years. The main part of patients $(60.7 \%)$ came from socio-economic disadvantaged backgrounds. BCG immunization coverage was $92.9 \%$; a contagion history was found in $42.9 \%$ of cases. Malnutrition was present in $82.1 \%$ and the combination HIV / tuberculosis were $17.8 \%$. Pulmonary tuberculosis was the most frequent clinical form (50\%). Sputum was positive in 2 children. Nodes location (35.7\%) was the main extrapulmonary form.

Conclusions: Pulmonary tuberculosis in children is common in sub-saharan Africa. National free care processing policy is welcome but a strengthening of diagnostic capacity will allow an optimal management of the child life infection.

\section{Introduction}

According to the World Health Organization (WHO), 6.3 million new cases of tuberculosis were recorded worldwide in 2016. Most cases occur in low socio-economic countries; the African region was affected by $25 \%$ of cases [1]. In the same year, new cases of tuberculosis in children under 15 years old represented around 6.9\% of all cases in the world [1]. In Burkina Faso, pulmonary tuberculosis is the most common form; It accounted for $83 \%$ of all reported cases in 2016 [2]. In 2015, the number of tuberculosis-related deaths among people under 15 years was estimated at 239,000 and cases of co-infection with HIV accounted for $17 \%$ [3]. As a result of its relative frailty and its inescapable contact with adults, the child is a favorite place for tuberculosis. However, the diagnosis of childhood tuberculosis, even in its pulmonary form, remains difficult, especially in developing countries due to lack of efficient means. The diagnosis is usually based on a non-specific arguments beam, such as concept of contagion, signs of tuberculous impregnation, chest X-ray images, and tuberculin intradermoreaction.

The aim of this study was to describe the epidemiological, clinical and paraclinical aspects of childhood tuberculosis in the pediatric department of Souro Sanou University Hospital Center in BoboDioulasso.

\section{Patients and Methods}

It was a cross-sectional descriptive study with prospective collection. It ran from January 1st to December 31st 2016, a 12-month recruitment period.

Were included in this study, children aged from 0 to 15 years old, in whom the diagnosis of tuberculosis was made during the period of study in the Department of Pediatrics. This diagnostic was based on anamnestic arguments (concept of contagion, signs of tuberculous impregnation, chronicity of signs, known HIV infection), clinical (pleuropulmonary signs, fistulized lymphadenopathy, spinal hump...) and laboratory (AFB in sputum, inflammatory syndrome, evocative chest X-ray, ultrasound...).

Patients were included consecutively according to the rate of admission during the collection period. The consent of parents or legal guardians was required before any inclusion.

The clinical and para-clinical data of each patient were collected daily at the level of the different hospitalization services of the pediatric department of Souro Sanou Hospital. The data were collected by apretested and validated questionnaire. They have been entered on the EPI data 3.1 software. The analysis was performed using STATA 12. The existence of statistical links between the variables of interest was investigated by $\mathrm{Chi}^{2}$ test. The link was considered significant for a "p" of less than $5 \%$ (risk $\alpha$ ).

\section{Results}

During the study period, 28 new cases of tuberculosis were recorded in the Department of Pediatrics of Souro Sanou Hospital, a hospital frequency of $0.2 \%$. There was a predominance of boys (17/28), with a sex ratioof 1.5 . The average age of the children was 8.3 years old with extremes of one month and 15 years. Two children were less than one year old (one month and six months; maternal story). The under five years group was eight. Ten children were between five and 10 years old

"Corresponding Author: Dr. SA Kissou, Higher Institute of Health Sciences (INSSA); Nazi Boni University (UNB) of Bobo-Dioulasso, Burkina Faso; Tel: + 226702476 34; E-mail: aimekissou@yahoo.fr

Citation: Kissou SA, Millogo JDC, Nikiema Z, Birba E, Cessouma R, et al. (2018) Childhood Tuberculosis in Sub-saharan Africa. Int J Pediatr Neonat Care 4: 138. doi: https://doi.org/10.15344/2455-2364/2018/138

Copyright: (c) 2018 Kissou et al. This is an open-access article distributed under the terms of the Creative Commons Attribution License, which permits unrestricted use, distribution, and reproduction in any medium, provided the original author and source are credited. 
Citation: Kissou SA, Millogo JDC, Nikiema Z, Birba E, Cessouma R, et al. (2018) Childhood Tuberculosis in Sub-saharan Africa. Int J Pediatr Neonat Care 4: 138. doi: https://doi.org/10.15344/2455-2364/2018/138

Page 2 of 5

and 10 others were over 10 years old; $71.4 \%$ of children over five years old. The area of residence was predominantly rural and involved 17 children. The 11 others were living in Bobo-Dioulasso.

Passive smoking was found in nine children. Two children did not receive the BCG vaccine. A concept of contagion was found in 12 children; the adult contaminant was one of parents in seven of them. Three underlying chronic diseases were found. These included malnutrition in 23 children, HIV infection in five children, and sickle cell disease in two children. These morbidities were sometimes associated.

The most common clinical signs were long-term fever, decreased play activities, chronic cough and night sweats. The other signs were often suggestive of the clinical form of tuberculosis (lymphadenopathies, spinal gibbosity, meningeal syndrome, etc.). Signs were often associated in the same patient. Table 1 is a summary of the clinical signs observed in children.

Figures 1, 2 and 3 are photographs of children of the series, respectively showing chest X-ray, fistulized lymphadenopathy, and spinal gibbosity.

The most common biological abnormalities were anemia and leukocytosis. Table II gives a summary of the biological abnormalities found in the patients.

\begin{tabular}{|l|l|l|}
\hline Signs / symptoms & Numbers & Percentages (\%) \\
\hline Drop in fun activities & 22 & 78.6 \\
\hline Long-term fever & 26 & 92.9 \\
\hline Night sweats & 18 & 64.3 \\
\hline Cough more than 14 days old & 19 & 67.9 \\
\hline hemoptysis & 1 & 3.6 \\
\hline Spinal gibbosity & 4 & 14.3 \\
\hline Peripheral lymphadenopathy & 8 & 28.6 \\
\hline Meningeal syndrome & 1 & 3.6 \\
\hline Liquid effusion & 7 & 25 \\
\hline Pallor & 1 & 3.6 \\
\hline Abdominal meteorism & 1 & 3.6 \\
\hline splenomegaly & 4 & 14.3 \\
\hline hepatomegaly & 4 & 14.3 \\
\hline icterus & 1 & 3.6 \\
\hline otorrhoea & 1 & 3.6 \\
\hline Oral candidiasis & 1 & 3.6 \\
\hline Paralysis of a limb & 1 & 3.6 \\
\hline
\end{tabular}

Table1: Most observed clinical signs of tuberculosis among children.

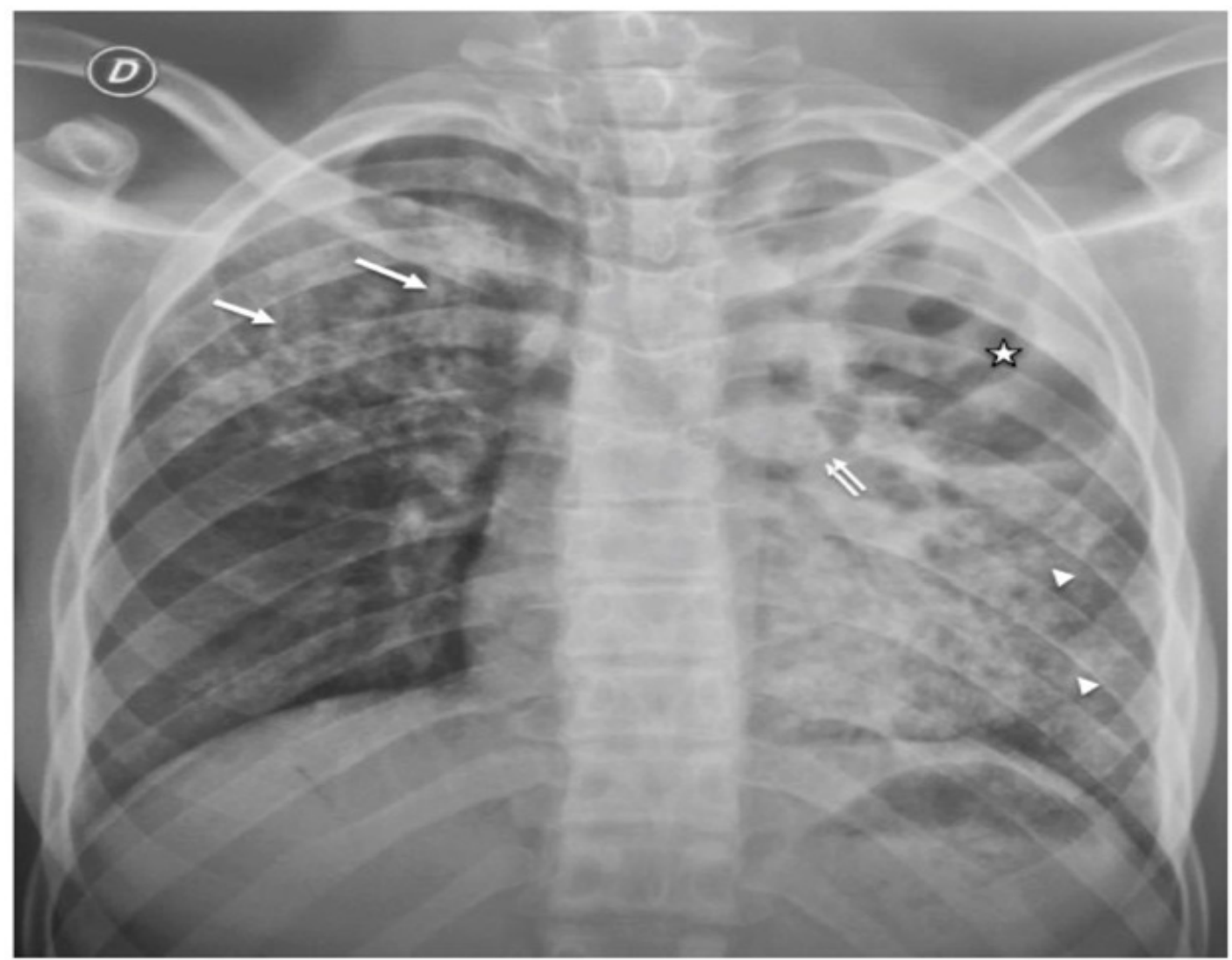

Figure 1: Chest X-ray of a 15 years old girl showing an interstitial syndrom:

- a vast cavern of the lingula (star) with a drainage bronchus (double arrow)

- a right apical infiltrate (arrow)

- and a left basal milial aspect (arrowhead) 
Citation: Kissou SA, Millogo JDC, Nikiema Z, Birba E, Cessouma R, et al. (2018) Childhood Tuberculosis in Sub-saharan Africa. Int J Pediatr Neonat Care 4: 138. doi: https://doi.org/10.15344/2455-2364/2018/138

Page 3 of 5

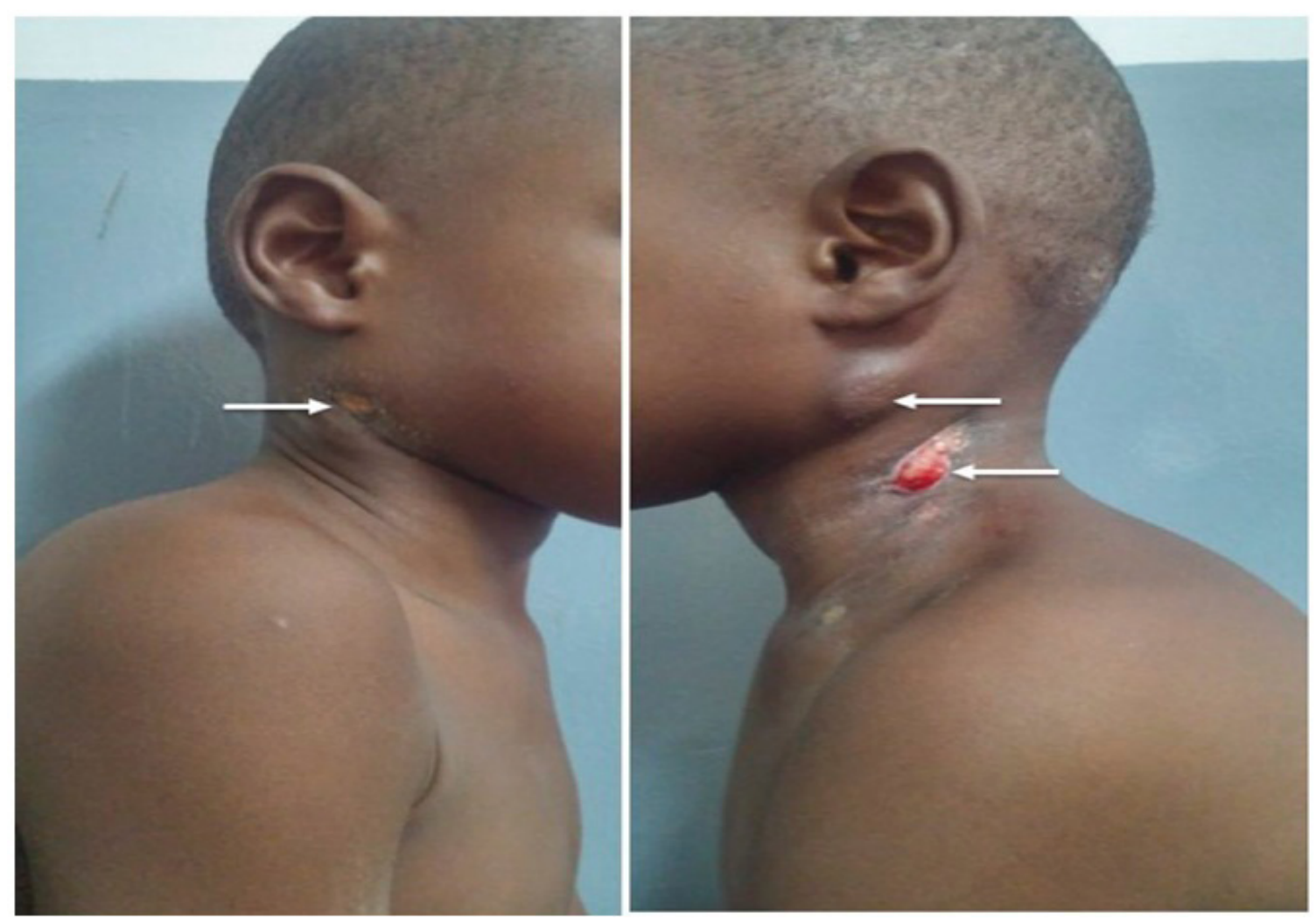

Figure 2: right (A) and left (B) profile photographs of a 4 years old boy presenting lymphadenopathies

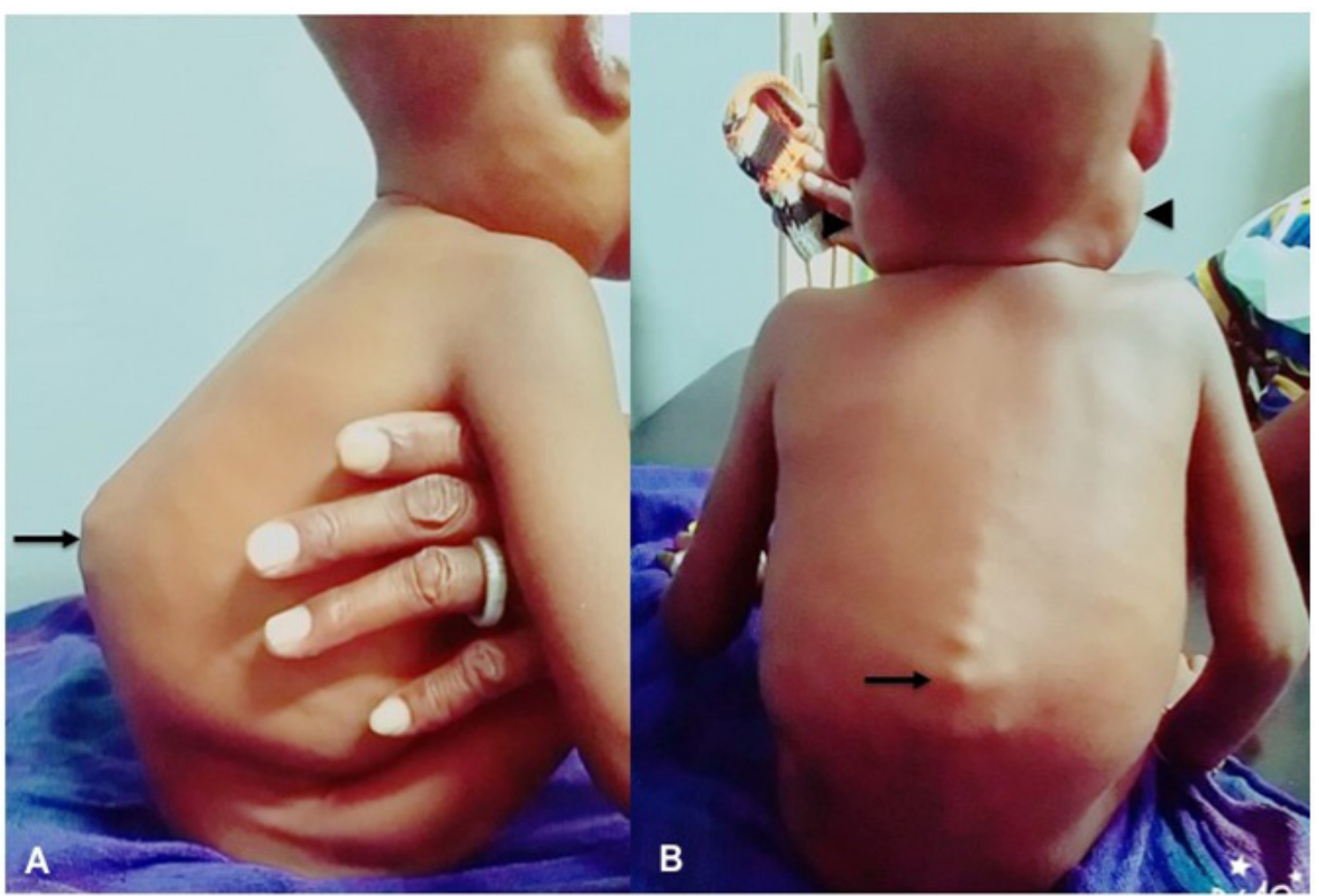

Figure 3: profile (A) and dorsal (B) photographs of a two years old infant with a Dorsolumbar gibbosity (arrows) and lymphadenopathies 


\begin{tabular}{|l|l|l|}
\hline Biological signs & Numbers & Percentages (\%) \\
\hline leukocytosis & 14 & 50 \\
\hline Anemia & $\mathbf{1 9}$ & $\mathbf{6 7 . 8}$ \\
\hline thrombocytopenia & 4 & 14.3 \\
\hline High CRP & 10 & 35.7 \\
\hline ASAT $\geq 2$ xNormal & 9 & 32.1 \\
\hline ALAT $\geq 2$ xNormal & 5 & 17.8 \\
\hline High azotemia & 4 & 14.3 \\
\hline Elevated creatinine & 11 & 39.3 \\
\hline
\end{tabular}

Table 2: Distribution of children according to biological abnormalities found.

Direct sputum examination was positive in only two children. These were tuberculosis cases with isolated pulmonary localization.

The GeneXpert test/ MTB / RIF performed in nine children was negative.

Chest X-ray was abnormal in 21 children. Pulmonary lesions were varied and dominated by parenchymal infiltrates. Cellular condensation was found in $32.1 \%$ of patients. Four cases of military radiological were observed. Table 3 illustrates the different lesions and their frequencies.

\begin{tabular}{|l|l|l|}
\hline lesions & Numbers & Percentage (\%) \\
\hline milestone & 4 & 14.3 \\
\hline caves & 2 & 7.1 \\
\hline infiltrates & 11 & 39.3 \\
\hline Alveolar condensation & 9 & 32.1 \\
\hline Bronchial syndrome & 4 & 14.3 \\
\hline Mediastinallymphadenopathy & 4 & 14.3 \\
\hline Fluid pleural effusion syndrome & 7 & 25 \\
\hline cardiomegaly & 2 & 7.1 \\
\hline
\end{tabular}

Table 3: Frequency of lesions observed on chest x-ray ofchildren with tuberculosis.

Abdominal ultrasonography was performed in 11 patients, showing numerous abnormalities, the most common being ascites and deep lymphadenopathy. These anomalies were often associated. Table 4 gives the synthesis of different abnormalities found in abdominal ultrasound.

\begin{tabular}{|l|l|l|}
\hline Ultrasound abnormalities & Numbers & Percentage (\%) \\
\hline Deep lymphadenopathies & 4 & 36.4 \\
\hline ascites & 6 & 54.5 \\
\hline $\begin{array}{l}\text { Magnesial aspects (Splenic, hepatic } \\
\text { and hepatosplenic) }\end{array}$ & 3 & 27.3 \\
\hline Homogeneous hepatomegaly & 2 & 18.2 \\
\hline Homogeneous splenomegaly & 1 & 9.1 \\
\hline Hepatosplenomegalyhomogeneous & 1 & 9.1 \\
\hline Psoas abscess & 0 & 0 \\
\hline Renal failure & 2 & 18.2 \\
\hline Intra-abdominaltissue formation & 2 & 18.2 \\
\hline
\end{tabular}

Table 4: Summary of abnormalities found on abdominal ultrasonography of children with tuberculosis.
In total, tuberculosis was unifocal in 13 children (46.4\%) and multifocal in 15 (53.6\%). The most frequent locations were lung (nine cases including seven associated with pleural involvement), lymph nodes and abdomen. Figure 3 illustrates different locations found.

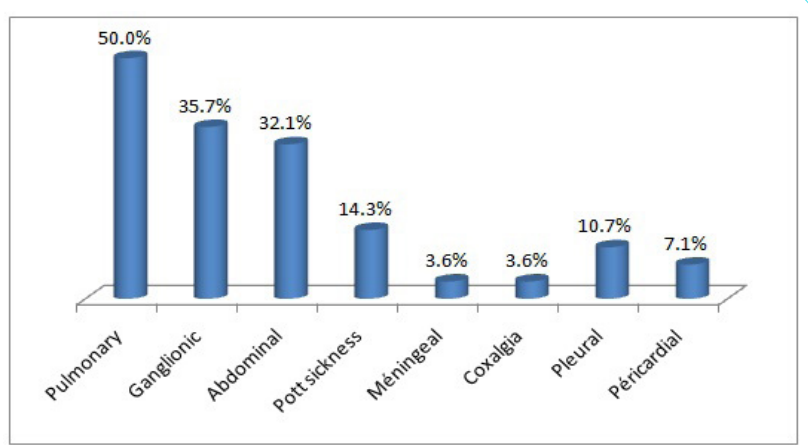

Figure 3: Distribution of different locations found in children with tuberculosis.

\section{Discussion}

\section{Epidemiologyand context}

Twenty-eight new cases were reported during our study. A hospital study in Togo reported an annual average of 18 cases [4]. The hospital frequency of $0.2 \%$ that we found reflects a relative rarity of tuberculosis in children. Under-reporting of cases is not excluded. Indeed, the multiplicity of clinical presentations in children can lead to diagnostic errors and the use of traditional medicine, favored by mystical beliefs. This is especially true since the majority of cases came from rural areas.

Children over five were the most numerous in our series, as reported in other African studies [4-6]. Nevertheless two young infants had been infected by their mothers. Parental contagion effect was found in $58.3 \%$ of the total cases where a concept of contagion was reported. Tuberculous familial contours of children have often been reported $[7,8]$. Almost all children had been vaccinated with BCG, thus demonstrating already the limits of this vaccine in the prevention of tuberculosis $[9,10]$. Factors favoring infection such as passive smoking reported by other authors [11], as well as malnutrition have been found in some of our patents. HIV infection, for its part, is recognized as a major circumstance for the occurrence of tuberculous infection in children. The advent of HIV has led to an upsurge in tuberculosis and the combination of HIV/TB is a source of high morbidity and mortality in the pediatric population $[5,12]$.

\section{Clinical and para-clinical signs}

The most common clinical signs were long-term fever, decreased play activities, chronic cough, and night sweats. This and other signs such as night sweats, asthenia, weight loss and so-called "tuberculous impregnation" were not always found in our patients. On the other hand, the fever concerned almost all of them (92.9\%). It is reported variably by different authors $[6,13]$. Anemia was the most common biological abnormality even though it was not often evident in the clinical setting. Anemia is indeed common during childhood tuberculosis; it is of inflammatory type directly related to the disease, but it can be aggravated by a deficiency anemia, especially in cases of malnutrition as in up to $82.1 \%(23 / 28)$ of our patients. 
Citation: Kissou SA, Millogo JDC, Nikiema Z, Birba E, Cessouma R, et al. (2018) Childhood Tuberculosis in Sub-saharan Africa. Int J Pediatr Neonat Care 4: 138. doi: https://doi.org/10.15344/2455-2364/2018/138

Page 5 of 5

\section{Diagnostic}

In the majority of cases, the diagnosis of tuberculosis was made on the basis of an amnestic, clinical and para-clinical presumptive arguments. It is the same in other works $[5,6,14]$. Diagnostic confirmation of childhood TB remains difficult, even in better working conditions and despite the use of powerful technologies such as PCR and the detection of interferon- $\gamma$.

\section{Location}

Pulmonary tuberculosis was the most common clinical form, the so-called misconception that children would mostly be extrapulmonary. This finding is shared by several authors in Africa $[6,15]$. However, a scarcity of bacillus forms is certainly related to the fact that tuberculosis of the child is often paucibacillary [16]. Reaching peripheral lymph nodes was the first extra pulmonary location. In fact, ganglionic tuberculosis is common in children, with a significant contribution from pathological anatomy to diagnosis $[17,18]$.

\section{Conclusion}

Tuberculosis remains a public health problem in developing countries and children are not spared. Diagnostic difficulties persist despite technological progress and efforts of states and organizations in the fight against this disease. BCG remains the order of the day, but prevention of childhood tuberculosis is primarily based on the detection and early treatment of cases in adults.

\section{Competing Interests}

The authors declare that they have no competing interests.

\section{References}

1. WHO (2017) Global tuberculosis report 2017. Geneva: World Health Organization. Licence: CC BY-NCSA 3.0 IGO.

2. WHO (2018) Tuberculosis country profiles; Estimates of TB and MDR-TB burden.

3. Dodd PJ, Yuen CM, Sismanidis C, Seddon JA, Jenkins HE, et al. (2017) The global burden of tuberculosis mortality in children: a mathematical modelling study. Lancet Glob Health 5: e898-906

4. Segbedji KAR, Djadou KE, Tchagbele OB, Kpegouni M, Bessi Kama LK et al. (2016) Tuberculose de l'enfant au Togo : aspects épidémiologiques, diagnostiques, thérapeutiques et évolutifs. Médecine et Santé Tropicales $26: 318-322$.

5. Flick RJ, Kim MH, Simon K, Munthali A, Hosseinipour MC, et al. (2016) Burden of disease and risk factors for death among children treated for tuberculosis in Malawi. Int J Tuberc Lung Dis 20: 1046-1054.

6. Houda S, Anissa B, Besma H, Jamel A, Hanadi O, et al. (2016) Tuberculose de l'enfant: une étude descriptive dans un service de pneumo-pédiatrie en Tunisie. La tunisieMedicale 94: 259-264.

7. Gendrel D, Nguyen Y, Lorrot M, Soulier M, Royer C, et al. (2006) Tuberculose de l'enfant après contage familial : une expérience en pédiatrie générale. Children tuberculosis after familial contamination: experience in general pediatrics.

8. Randriatsarafara FM, Vololonarivelo BEE, Rabemananjara NNG Randrianasolo JBO, Rakotomanga JDM, et al. (2014) Facteurs associés à la tuberculose chez l'enfant au Centre Hospitalier Universitaire MèreEnfant de Tsaralalàna, Antananarivo: une étude cas-témoins. Pan Afr Med J 19: 224.

9. Chang KC, Leung CCL (2017) BCG Immunization: Efficacy, Limitations and Future Needs; Handbook of Global Tuberculosis Control.
10. Vasconcelos-Junior AC, Araújo-Filho JA, da Silva EB, de Sousa EM, Kipnis A, et al. (2009) Limitations of the BCG vaccine and new prophylaxis strategies against human tuberculosis; Einstein 7: 383-389.

11. Adetifa IMO, Kendall L, Donkor S, Lugos MD, Hammond AS, et al. (2017) Mycobacterium tuberculosis Infection in Close Childhood Contacts of Adults with Pulmonary Tuberculosis is Increased by Secondhand Exposure to Tobacco. Am J Trop Med Hyg 97: 429-432.

12. Adamu AL, Aliyu MH, Galadanci NA, Musa BM, Gadanya MA, et al. (2017) Deaths during tuberculosis treatment among paediatric patients in a large tertiary hospital in Nigeria. PLOS ONE 12: 0183270.

13. Swaminathan S, Datta M, Radhamani MP, Mathew S, Reetha AM, et al. (2008) A profile of bacteriologically confirmed pulmonary tuberculosis in children. Indian Pediatr 45: 743-747.

14. Ogbudebe CL, Adepoju V, Ekerete-Udofia C, Abu E, Egesemba G, et al. (2018) Childhood Tuberculosis in Nigeria: Disease Presentation and Treatment Outcomes; Health Serv Insights 11: 1178632918757490.

15. Wobudeya E, Sekadde-Kasirye M, Kimuli D, Mugabe F, Lukoye D, et al. (2017) Trend and outcome of notified children with tuberculosis during 2011-2015 in Kampala, Uganda. BMC Public Health 17: 963.

16. Chiang SS, Swanson DS, Starke JR (2015) New Diagnostics for Childhood Tuberculosis. Infect Dis Clin North Am 29: 477-502.

17. Rebecca B, Chacko A, Verghese V, Rose W (2018) Spectrum of Pediatric Tuberculosis in a Tertiary Care Setting in South India. J Trop Pediatr.

18. Kritsaneepaiboon S, Andres MM, Tatco VR, Lim CCQ, Concepcion NDP, et al. (2017) Extrapulmonary involvement in pediatric tuberculosis. PediatrRadiol 47: 1249-1259. 